\title{
The spectrum of placental pathology in a public v. private laboratory practice in Gauteng Province, South Africa
}

\author{
M J Savage-Reid, ${ }^{1,2}$ MB ChB, Dip Obs (SA); C A Wright, ${ }^{1,3}$ MB BCh, FC Path, FRC Path, MMed (Anat Path), FIAC, PhD; \\ R Wadee, ${ }^{1,2} \mathrm{MB}$ BCh, FC Path, MMed (Anat Path), Dip RCPath, FAcadTM, PhD \\ ${ }^{1}$ Department of Anatomical Pathology, Faculty of Health Sciences, University of the Witwatersrand, Johannesburg, South Africa \\ ${ }^{2}$ National Health Laboratory Services, Johannesburg, South Africa \\ ${ }^{3}$ Lancet Laboratories, Richmond, Johannesburg, South Africa
}

Corresponding author: M J Savage-Reid (mjsavagereid@gmail.com)

\begin{abstract}
Background. Laboratory information systems have a wealth of patient and health data that can be made available for research. These data can serve to better inform healthcare delivery and formulation of policies. The placenta is just one histopathology laboratory specimen that can provide such insight, particularly with regard to maternal and neonatal healthcare.

Objectives. To describe the spectrum of placental pathology in a private and public laboratory and to ascertain implications for improved maternal and neonatal healthcare and policies.

Methods. We conducted a retrospective descriptive study of placental histopathology reports from Lancet Laboratories and the National Health Laboratory Service (NHLS) in Johannesburg over a 1-year period (August 2017 - July 2018). The reports were categorised according to the 2014 Amsterdam Placental Workshop Group Consensus Statement and the percentages of each diagnostic entity compared between the two laboratories. These diagnostic categories included ascending infection, maternal vascular malperfusion (MVM), fetal vascular malperfusion, haematogenous infection, chronic villitis of unknown aetiology, retroplacental haemorrhage, no specific pathological changes and 'other'. Differences in maternal age and gestational age were also compared.

Results. There were 1172 and 946 placentas that were entered into the study at Lancet and NHLS, respectively. MVM was the most prevalent pathology seen in both laboratories $(40.6 \%$ and $47.7 \%$; $p=0.3193)$. Mean maternal and gestational age were both higher in the private system (both $p<0.0000$ ).

Conclusion. Differences in placental pathology were multifactorial and reasons may include differences in socioeconomic status and resources, clinical and laboratory policies and practices, as well as pathologist training and expertise. Clear clinical guidelines for the submission and histopathological examination of the placenta are required to better inform neonatal and maternal healthcare and policies. In our divided healthcare system, collaborative medical research is not only possible between the public and private sectors but also necessary to achieve better healthcare and equity for patients in South Africa.
\end{abstract}

S Afr J Obstetr Gynaecol 2020;26(2):54-59. https://doi.org/10.7196/SAJOG.2020.v26i2.1599

Healthcare systems and policies have been compared across different countries but there has been little agreement among scholars with respect to assessment of the quality thereof. ${ }^{[1]}$ A study published in The Lancet Global Health in 2018 sought to give recommendations to raise the quality of a healthcare system. ${ }^{[2]}$ One such recommendation highlighted the inability of government health ministries to accomplish improved quality alone and the necessity to partner with the private sector. ${ }^{[2]}$ In South Africa (SA), the health sector comprises a private sector serving $\sim 16 \%$ of the total population and a public sector serving the remaining $84 \%$. The former contributes disproportionately towards half of the country's total expenditure on healthcare. ${ }^{[3]}$ While health outcome statistics are not always consistently reported across sectors, ${ }^{[3]}$ both nevertheless contribute toward overall improved quality healthcare in the country, individually and collaboratively. As such, one would expect a growing body of collaborative research between SA's two healthcare systems, with the aim of providing quality care for all. Sadly, there is no such body of research.

Within these two healthcare systems, the histopathologist plays a pivotal role in the improvement of the quality of both population healthcare and health policies, ${ }^{[4-5]}$ particularly because of their access to abundant patient data and laboratory results contained in laboratory information systems. ${ }^{[4]}$ One histopathology specimen that offers a wealth of information and that has already been used in improving clinical healthcare and informing healthcare policies is the placenta. More specifically, the placenta is key to improving the quality of maternal and perinatal health ${ }^{[6-8]}$ especially in resourcelimited settings. ${ }^{[7]}$

This study aimed to describe and compare the spectrum of placental pathology seen at Lancet Laboratories, Richmond, Johannesburg (private healthcare sector) and the National Health Laboratory Services (NHLS) at Charlotte Maxeke Johannesburg Academic Hospital (CMJAH) (public healthcare sector) over a 1-year period. No such comparative study exists and very few placental pathology studies have been conducted in SA hospitals. ${ }^{[9-11]}$ The present study therefore adds to the growing pool of placental pathology research in SA and seeks to pioneer public-private collaboration, with the aim of improving SA maternal and perinatal care and policies.

The primary objectives of this study included capturing the number of placental reports from each sector for the 
specified period of time, categorising the diagnosis of each report based on the Amsterdam Workshop Group Consensus Statement on the definitions of placental lesions, ${ }^{[12]}$ calculating their respective percentages and comparing the differences between each sector. Secondary aims included analysing these findings and the possible implications for the management of maternal and perinatal conditions and establishing possible recommendations for subsequent health reforms and policies in SA's healthcare system.

\section{Methods}

We conducted a retrospective descriptive study. Following ethical clearance by the University of the Witwatersrand's Human Research Ethics Committee (ref. no. M180827), data were collected by searching both the Lancet Laboratories (Richmond, Johannesburg) and NHLS (CMJAH) databases using the Systematised Nomenclature of Medicine Clinical Terms (SNOMED CT) tissue codes 'placental structure' and 'entire placenta' for the period 1 August 2017 to 31 July 2018. The initial data were captured on Microsoft Excel (Microsoft Corp., USA) spreadsheets.

The parameters included in the searches were hospital, patient age (years), gestation (weeks and singleton or multiple pregnancy) as well as the full placental histopathology reports with the conclusion/ diagnosis. Ethnicity is inconsistently recorded on laboratory request forms and was thus not included.

Each placental histopathology report was then reviewed and, based on the findings and diagnosis, placed into broader diagnostic categories according to the 2014 Amsterdam Placental Workshop Group Consensus Statement. ${ }^{[12]}$ The diagnostic categories for our study included ascending infection (acute chorioamnionitis, funisitis, vasculitis), maternal vascular malperfusion (MVM), fetal vascular malperfusion (FVM), haematogenous infection (acute and chronic villitis, acute intervillositis), chronic villitis of unknown aetiology (VUE), retroplacental haemorrhage (RPH), no specific pathological changes (NSPC) and 'other'. Cases with findings falling into more than one category were assigned multiple categories.

Cases from the NHLS dataset that were designated as 'other' or otherwise could not be accurately placed into one or more of the diagnostic categories had their slides retrieved and reviewed by an experienced histopathology consultant (RW) and a senior histopathology registrar (MSR). Upon review and consensus diagnosis, each was then appropriately re-categorised into the diagnostic categories. In a case where consensus could not be reached, slides were reviewed by a second histopathology consultant with many years of experience in placental pathology (CW).

Only NHLS cases were reviewed because of the heterogeneity in reporting of placental specimens from this institution and difficulty in categorising according to the Amsterdam consensus criteria. At the NHLS, placentas were reported by different pathologists with varied placental pathology interest and expertise. In contrast, all cases seen at Lancet Laboratories during this time period were reported by one pathologist (CW) using a consistent reporting template.

Inclusion criteria were reports of complete placental specimens that were inclusive of umbilical cord, membranes and placental disc(s). Chorionic disc weight was also an inclusion criterion. Where a gestational age was not available, placental weights were then used to calculate the mean gestational age using a table of reference values for singleton and twin placental weights in relation to gestational age. ${ }^{[13]}$
Cases were excluded if there was an incomplete placental report (absent umbilical cord and/or membranes and/or placental disc), severe autolysis or severe processing artefact (precluding accurate histological assessment) and cases from public hospitals that were submitted to Lancet Laboratories. This kept the comparison strictly between placentas received from public hospitals reported by NHLS pathologists with that of placentas received from private hospitals reported by the pathologist at Lancet Laboratories.

The final datasets for analysis were captured onto Microsoft Excel spreadsheets in single table format. Mean percentages were calculated for patient age and gestational age, and the medians thereof, and recorded. The percentage of NHLS specimens derived from academic hospitals in comparison with secondary hospitals was also captured. Gestation (singleton or multiple pregnancy) and each of the eight diagnostic categories were recorded as a percentage of the total number of cases for each of the institutions. Cases showing multiple diagnostic entities, such as MVM and FVM, had each entity included in the calculated percentages for the respective categories.

To determine any statistically significant differences between the proportion estimated from Lancet and the NHLS, we used a two-tailed $Z$-proportion test with significance level set at $5 \%$. Statistical significance between average maternal and gestational ages was performed using a two-tailed independent $t$-test with significance set at $5 \%$.

\section{Results}

The initial Lancet Laboratories data extraction yielded 1362 cases; 190 cases were excluded yielding a total of 1172 cases for the period examined. Of the 190 cases that were excluded, 135 were excluded because they originated from public hospitals.

The initial NHLS data extraction yielded 1122 cases; 156 cases were excluded in the first round of analysis prior to reviewing slides and 966 cases remained. Thereafter, 132 of the cases were selected for slide review (13.7\% of the 966 NHLS cases and $6.2 \%$ of the combined NHLS and Lancet cases ( $N=2$ 138). The reviewed cases comprised 29 cases that were classified as 'other' only and 103 cases that could not be accurately classified into a diagnostic category based on the original histopathology report. From these reviewed NHLS cases, an additional 20 cases were excluded from the study and a total of 946 cases were included in the study (Fig. 1).

Less than a tenth of the NHLS cases $(6.24 \% ; n=59)$ were submitted from secondary hospitals and the remainder were derived from tertiary and quaternary (academic) hospitals.

Both the mean maternal and gestational age showed statistically significant differences between the two laboratories $(p<0.0000)$ (Table 1). The number of multiple pregnancies was not statistically significant between the two laboratories $(p=0.7564)$ (Table 1).

There were statistically significant differences in FVM $(p=0.0001)$, RPH $(p=0.0000)$, ascending infection $(p=0.0000)$ and VUE $(p=0.0000)$ between the two laboratories (Table 2). However, there was no statistically significant difference in 'other' $(p=0.6374)$, $\operatorname{MVM}(p=0.3193)$, haematogenous infection $(p=0.3062)$ and NSPC ( $p=0.2676$ ) between the two laboratories (Table 2).

The 'other' pathologies comprised a broad spectrum of findings across both institutions and these individual diagnoses were not all captured. These 'other' entities included, but were not limited to, maternal floor infarction, chronic histiocytic intervillositis, umbilical cord pathology (such as single umbilical artery and hypercoiling) and chorangiosis. Of interest, one case of metastatic melanoma 
was identified in the Lancet Laboratories' dataset and one case of a diffuse large B-cell lymphoma was identified in the NHLS dataset.

\section{Discussion}

The majority of the NHLS cases came from academic hospitals, where specialist obstetricians practise and train registrars. The secondary hospitals and by extension, labour wards, are still largely serviced by community service medical officers and medical interns with less obstetric expertise. ${ }^{[14]}$ In contrast, the private sector comprises entirely specialist obstetricians. This difference in obstetric experience may explain a disparity in the awareness of criteria warranting submission of a placenta for histological evaluation. These indications for placental histopathological examination can be conceptualised as fetal, neonatal and maternal indications. ${ }^{[15]}$ Some healthcare systems in other countries have published guidelines for histopathological placental examination; ${ }^{[16]}$ however, no such national guidelines exist for the SA healthcare system, although local guidelines do exist and are variably observed. On the other hand, tertiary and quaternary hospitals receive referrals for complicated pregnancies, so these hospitals may see a greater number of preterm deliveries which may account for the lower average gestational age. Preterm delivery has numerous risk factors. Of these,

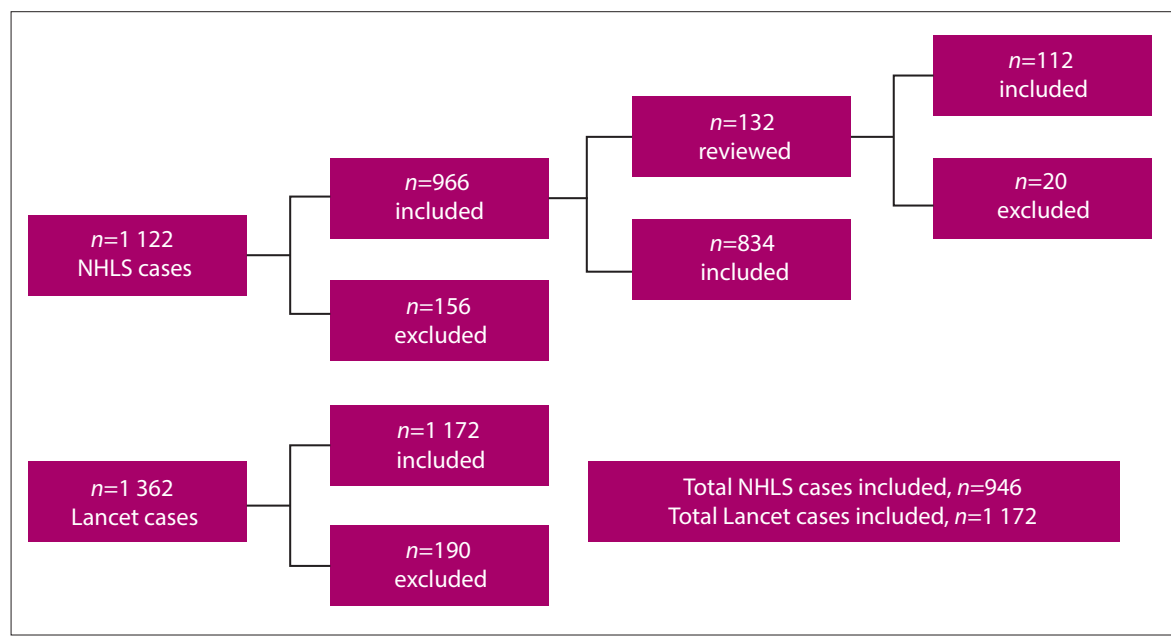

Fig. 1. Flow diagram summarising the exclusion process and number of cases included from the initial data extraction from each laboratory.

hypertensive disorders in pregnancy are among the greatest risk factors for preterm delivery, ${ }^{[17]}$ and a higher frequency of MVM has already been established in the NHLS data.

There was no statistically significant difference in MVM between the two laboratories. MVM of the placental bed is the result of trophoblast dysfunction and abnormal maternal artery remodeling during placental development (Fig. 2). ${ }^{[18]}$ Classically, this placental finding has been associated with a clinical diagnosis of pre-eclampsia ${ }^{[19]}$ and other hypertensive disorders of pregnancy. ${ }^{[20]}$ Globally, 1.4 billion people had hypertension in $2010^{[21]}$ and more than $30 \%$ of adults were estimated to have hypertension in SA. ${ }^{[2]}$ The prevalence of hypertensive disorders of pregnancy is $12.5-38 \%$ in SA mothers ${ }^{[23-24]}$ and it causes significant maternal morbidity and mortality, accounting for $18 \%$ of maternal deaths. ${ }^{[25]}$ This is in keeping with the high percentage of MVM in submitted placentas from both public and private hospitals. Another placental study performed at a tertiary public hospital in SA showed that $32.1 \%$ of intrauterine fetal death (IUFD) cases demonstrated MVM in the accompanying placenta. ${ }^{[9]}$ This figure is not as high as the $47.7 \%$ we found in the public laboratory nor the $40.6 \%$ in the private laboratory. Although not statistically significant, the slightly higher percentage of MVM observed in the public laboratory compared with private laboratory may be

Table 1. Comparison of obstetric parameters for placental samples

$\begin{array}{llll} & & & \\ \text { Parameters } & \begin{array}{l}\text { Lancet } \\ \boldsymbol{n}(\%)^{*}\end{array} & \begin{array}{l}\text { NHLS } \\ \boldsymbol{n}(\%)^{*}\end{array} & \begin{array}{l}\boldsymbol{p} \text {-value } \\ \hline \text { Maternal age (years), mean (median) }\end{array} \\ \text { Gestational age (weeks), mean (median) } & 33.33(34) & 28.37(28) & <0.0000 \\ \text { Singleton pregnancy placentas } & 32.69(35) & 27.43(28) & <0.0000 \\ \text { Multiple pregnancy placentas: twins or triplets only } & 93.69 & 95.35 & - \\ \text { NHLS = National Health Laboratory Service. } & 6.31 & 4.65 & 0.7564 \\ \text { *Unless otherwise specified. } & & & \end{array}$

Table 2. Comparison of placental diagnostic categories

\begin{tabular}{|c|c|c|c|}
\hline Diagnostic category & $\begin{array}{l}\text { Lancet }(\mathrm{n}=1172), \\
n(\%)^{\star}\end{array}$ & $\begin{array}{l}\text { NHLS }(\mathrm{n}=946) \\
n(\%)^{*}\end{array}$ & $p$-value \\
\hline Maternal vascular malperfusion & $476(40.6)$ & $451(47.7)$ & 0.3193 \\
\hline Retroplacental haemorrhage & $568(48.5)$ & $114(12.1)$ & 0.0000 \\
\hline Ascending infection & $143(12.2)$ & $356(37.6)$ & 0.0000 \\
\hline Haematogenous infection & $36(3.1)$ & $54(5.7)$ & 0.3062 \\
\hline Villitis of unknown aetiology & $258(22.0)$ & $3(0.3)$ & 0.0000 \\
\hline Other & $130(11.1)$ & $83(8.8)$ & 0.6374 \\
\hline No specific pathological changes & $57(4.9)$ & $85(9.0)$ & 0.2676 \\
\hline
\end{tabular}


due to the fact that tertiary and quaternary hospitals serve as points of referral for complicated pregnancies.

The private healthcare users' mean maternal age was higher than that of mothers using the public healthcare system. This may be in part due to differences in socioeconomic status. Socioeconomic disparities between the public and private healthcare systems are well-documented in SA. ${ }^{[26-27]}$ A survey-based study conducted in four provinces of SA in 2012, including the Gauteng Province, evaluated rates of adolescent pregnancies and contributing factors and found that $19.2 \%$ of young women had an adolescent pregnancy, and unemployment and poverty were associated with adolescent pregnancy. ${ }^{[28]}$ Another proposed contributing factor to the differences in average maternal age between the two sectors is accessibility and affordability of contraceptives. Women with financial means may opt for a contraceptive method of their choice from the private sector, while women using the public healthcare system have to overcome barriers such as travel costs to access free contraception in the public hospitals. Furthermore, public facilities may not always have the full repertoire of contraceptive options available. ${ }^{[29]}$

We observed a statistically significant difference in the percentages of diagnosed VUE, FVM, ascending infection and RPH between the two laboratories (Fig. 2).

VUE is diagnosed when an identifiable infectious aetiology has been excluded and a possible immune-based aetiology is largely based on its increased incidence in patients with either autoimmune conditions or those having fallen pregnant by assisted/in vitro fertilisation (IVF) with donor ova. ${ }^{[30]}$ There are unfortunately no data available comparing the prevalence of autoimmune conditions between the two healthcare sectors. However, IVF partly accounts for the increased numbers of VUE within the Lancet data. IVF costs on average between ZAR40 000 - 50000 per treatment cycle in $\mathrm{SA}^{[31]}$ and is largely only available in the private healthcare sector. Only three public/academic facilities offer IVF, namely, Steve Biko, Tygerberg and Groote Schuur hospitals, ${ }^{[32]}$ none of which fall within the CMJAH drainage area. What more likely explains the markedly decreased number of VUE in the NHLS data is a paucity of tissue sampling. On average, only two sections of placental parenchyma are sampled at the CMJAH NHLS laboratory per placental specimen. This lies in stark contrast to the seven blocks of placental parenchyma per placenta sampled at Lancet Laboratories. At least six sections are required to detect 85 - 95\% of cases of VUE. ${ }^{[33]}$ Lastly, a previous study reported that VUE primarily affects two main groups of pregnant women; namely, younger women of lower socioeconomic status with a history of sexually transmitted infections, and older women of higher socioeconomic status often with a history of multiple miscarriages. ${ }^{[3]}$ The latter group is accounted for in the Lancet dataset; however, the former group is unaccounted for in the NHLS dataset and this suggests gross under-sampling of submitted placental specimens.

The higher RPH may be explained by the traumatic haemorrhage associated with removal of the placenta during caesarean section (CS) and the surgery itself. ${ }^{[35]} \mathrm{CS}$ rates are significantly higher in the private healthcare system (65\%) compared with the public healthcare system $(15-20 \%)$ in SA. ${ }^{[36]}$ Interestingly, the CS rates were $76.9 \%$ and $29.4 \%$ for the private and public healthcare sectors in the Gauteng Province in 2017 - 2018, respectively. ${ }^{[37]}$

With respect to FVM, we propose that a reason for the difference is a lack of awareness of criteria for diagnosing this entity among public/NHLS pathologists. FVM is a relatively new term that was introduced by the Amsterdam International Consensus group of placental pathologists in 2014, ${ }^{[38]}$ and as such, pathologists who are not aware of these updates or see placentas infrequently may miss this entity. The use of templates and checklists in histopathology reporting is invaluable. ${ }^{[39]}$ These not only aid the pathologist in making an accurate and clinically helpful diagnosis but may also aid in effectively communicating such findings to the clinician for clinical utility and application. ${ }^{[40]}$ Within the time period of our study, a reporting template for the placental histopathology reports
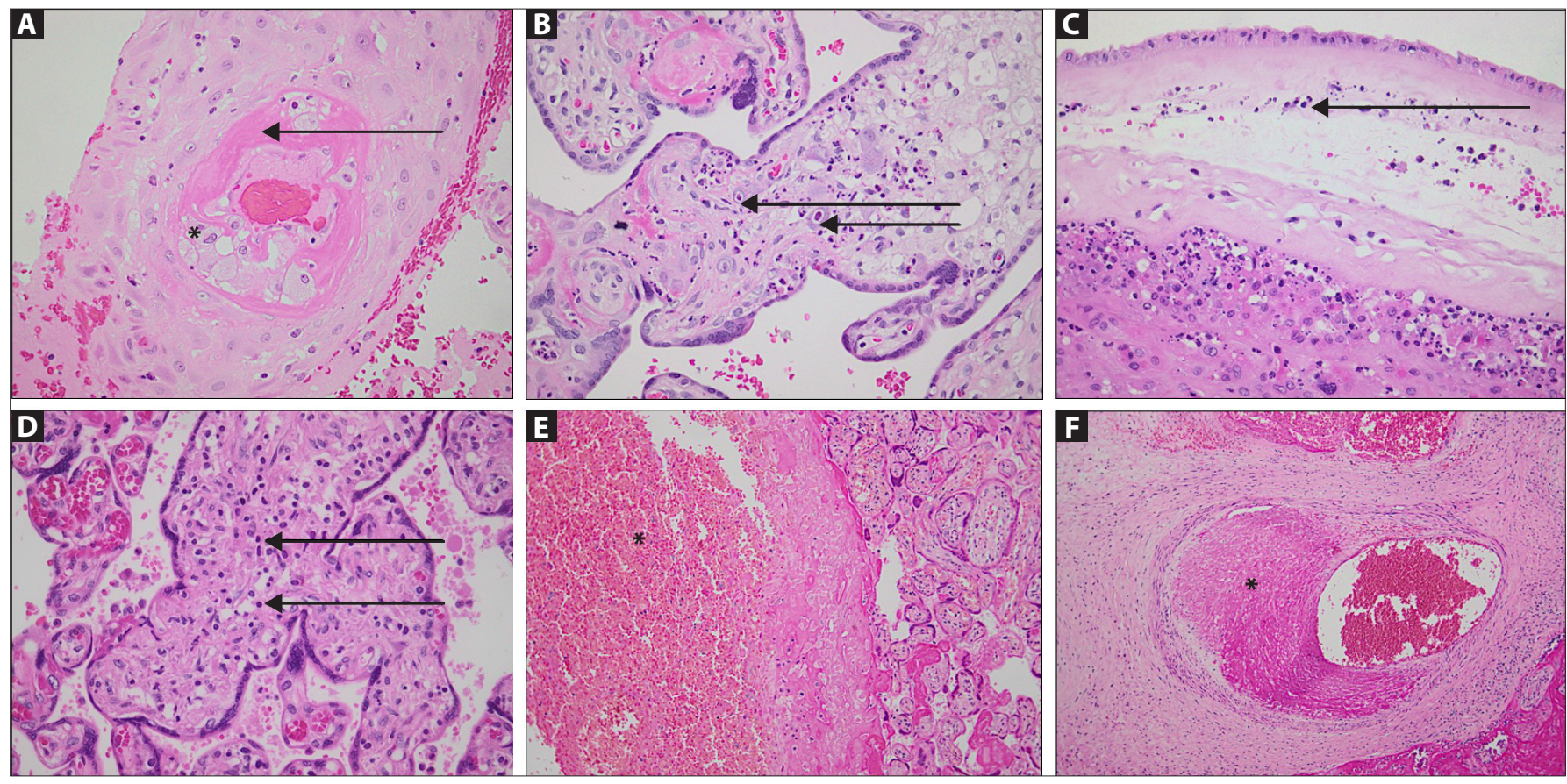

Fig. 2. (A) Fibrinoid necrosis (arrow) and atherosis (asterisks) constituting maternal decidual vasculopathy in MVM. (B) Villitis with cytomegalovirus inclusions (arrows). (C) Acute chorioamnionitis with neutrophils (arrow) present within the chorion. (D) Numerous lymphocytes (arrows) within a villus seen in VUE. Original magnification 400× (A-D). (E) Retroplacental haemorrhage (200×) (asterisks). (F) Fibrin thrombus $(100 \times)$ (asterisks) in FVM. MVM = maternal vascular malperfusion; VUE = villitis of unknown aetiology; FVM = fetal vascular malperfusion. 
was already in use at Lancet and this had not yet been routinely adopted and applied at the NHLS laboratory based at CMJAH. This may further explain the lower FVM and VUE reporting in the NHLS data. An additional contributing factor that we alluded to earlier is the fact that the Lancet data was reported on by a single pathologist with many years of experience in placental pathology who reports exclusively on placentas compared with the NHLS reporting that is done by pathology 'generalists.' The specialist-generalist debate is an ongoing debate within clinical medicine ${ }^{[41]}$ and has already been hinted at within the field of pathology. ${ }^{[42]}$ Our study perhaps gives some evidence to argue a case for sub-specialisation within the field of pathology. However, there is a lack of resources, training and a critical mass of pathologists to support sub-specialisation within the field. Hence, there is a gross shortage of pathologists and a need for increased training of pathologists has already been established in Africa. ${ }^{[4]}$ Although SA has the highest concentration of pathologists in Africa, we still only have 100 pathologists per 55 million people as of $2016^{[4]]}$ and the vast majority of them are practising within the private healthcare sector. ${ }^{[45]}$

The last significant placental pathology difference between the two sectors was the increased ascending infection in the NHLS data (37.6\%). This is comparable to that found in the aforementioned SA placental study where $34.5 \%$ of IUFD cases had placental evidence of acute chorioamnionitis. ${ }^{[9]}$ Risk factors for both clinically and histopathologically diagnosed acute chorioamnionitis are many and these include prolonged rupture of membranes, prolonged labour, meconium passage, multiple vaginal examinations, epidural anaesthesia, existing genital tract infection, bacterial vaginosis, prematurity and foreign bodies such as a cervical cerclage. ${ }^{[46]}$ A lower average gestational age in NHLS data was established and the increased ascending infection in this population group may have contributed to prematurity. A previous study conducted in Soweto, $\mathrm{SA}^{[24]}$ showed that stillbirths were mostly attributed to maternal medical conditions (particularly hypertensive disorders), placental or fetal infections and pathological placental conditions. The most cultured bacterium in invasive fetal infections is group B streptococcus. ${ }^{[2]}$ Group B streptococci are also among the common bacterial causes of acute chorioamnionitis ${ }^{[4]}$ and the incidence of group B streptococcal invasive disease is high in SA. ${ }^{[48]}$ Mothers are not routinely screened for vaginal group B streptococcus during pregnancy in the public healthcare system, whereas screening is more frequently performed in the private healthcare system (Dr Christopher Thomas, personal communication, 08 June 2020). This may also account for the higher percentage of ascending infection in the NHLS data. Numerous studies have made compelling cases for administering group B streptococcal vaccination to pregnant mothers ${ }^{[24,48-50]}$ and our study perhaps provides possible further evidence from a histopathological perspective.

\section{Study limitations and strengths}

One limitation of our study is that it only considers submitted placental specimens and is not a representation of all births. Furthermore, the data are representative of only one private laboratory and only hospitals that submit histopathology specimens to the NHLS CMJAH laboratory, which are predominantly academic hospitals. Thus, the data may not be truly representative of the burden of placental disease and its applicability to clinical practice across all medical facilities, especially in primary and secondary care public facilities. An additional limitation regarding the privately submitted placentas is the cost to the patient. Patients on limited medical aids or those who cannot afford the costs of submitting their placentas for histopathological examination may have led to a further decrease in submitted placental specimens from all private deliveries.

A major strength of our study is that this is the first study that has directly compared data between a public and private laboratory in SA. Collaboration between these two entities may assist or even be essential in increasing SA's progress towards achieving the sustainable development goals (SDGs).

Major recommendations emerging from this study are threefold. Firstly, we recommend that clinicians and policymakers develop clear guidelines for submission of the placenta for histopathological examination in their private practices or institutions. These should clearly lay out the fetal, maternal and neonatal indications. Placental histopathological findings will thus be of greater value in informing current management of mother and/or neonate, as well as inform management of future pregnancies. In a litigious society, histopathological examination of the placenta is invaluable ${ }^{[51]}$ and this further highlights the need for clear guidelines for the submission of the placenta for histopathological examination. Also, there is perhaps some evidence from our study to further motivate for the implementation of universal screening for prepartum group B streptococcal colonisation.

Secondly, we recommend that anatomical pathologists are made aware of the common placental pathological entities. The placenta is a common specimen, and the findings can have major clinical and/or legal implications. Placental pathology training workshops may serve to better equip pathologists in diagnosing placental pathology and more focused training at the registrar level would be of value. Increasing the number of pathology registrar posts will also aid in addressing the shortage of pathologists and may also encourage pathologists to pursue sub-specialisations within pathology. Furthermore, important recommendations for the NHLS are to adopt a placental histopathology reporting template and to perform more extensive sampling of placental specimens to adequately detect key pathologies. Where resources may restrict this at the NHLS, carefully selecting placentas for more sampling based on the clinical history provided on the laboratory request forms (e.g. a patient with a poor obstetric history or a baby with low Apgars) may be an option.

Thirdly, we recommend further collaboration in research between the public and private sectors. This study has illustrated the wealth of information available for research within the private laboratory sector, as well as its accessibility for researchers. There is not only a paucity of placental histopathological data in SA but also in research comparing the two healthcare systems that serve our country.

\section{Conclusions}

Histopathological examination of the placenta is an important resource available to clinicians. Apart from contributing to the understanding of the pathogenesis of different diseases, it invaluably contributes to the clinical management of mother, neonate and future pregnancies. In a healthcare system divided by socioeconomic status and resources, understanding the differences in maternal and neonatal pathology between these two health sectors is critical for informing clinical management and policymaking for maternal and neonatal wellbeing. Our study has not only provided insights into the differences in pathology between the two sectors but also the value of the placenta and the need for further private-public collaborative research. 


\section{RESEARCH}

Declaration. This study was conducted in partial fulfilment of requirements of an MMed (Anat Path) degree.

Acknowledgements. We thank Mrs Zvifadzo Matsena-Zingoni (Division of Epidemiology and Biostatistics, School of Public Health, Faculty of Health Sciences, University of Witwatersrand) for her help with the statistical analysis and Mr Abel Ndlovu for his help with the retrieval of slides for review. Author contributions. CW conceived the study. MSR performed the data collection and wrote the manuscript. CW and RW revised the manuscript. All authors approved the manuscript for publication.

Funding. None.

\section{Conflicts of interest. None.}

1. Cacace M, Ettelt S, Mays N, Nolte E. Assessing quality in cross-country comparisons of health systems and policies: Towards a set of generic quality criteria. Health Policy 2013;112(1-2):156-162. https://doi.org/10.1016\%2Fj.healthpol.2013.03.020

2. Kruk ME, Gage AD, Arsenault C, et al. High-quality health systems in the sustainable development goal era: Time for a revolution. Lancet Glob Health 2018;6(11):e1 196-e1252. https://doi.org/10.1016\%2Fs2214 $109 \times 2818 \% 2930386-3$

3. Ranchod S, Adams C, Burger R, et al. South Africa's hospital sector: Old divisions and new developments.S Afr Health Rev 2017;2017(1):101-109. https://hdl.handle.net/10019.1/107608

4. Gross DJ, Kennedy M, Kothari T, et al. The role of the pathologist in population health. Arch Pathol Lab Med 2019;143(5):610-620. https://doi.org/10.5858\%2Farpa.2018-0223-cp

5. Romano RC, Allen TC, Blessing MM. The essential role of pathologists in health care and health policy. Arch Pathol Lab Med 2015;139(4):441-444. https://doi.org/10.5858\%2Farpa.2014-0335-ed

6. Redline RW. Placental pathology: Is it time to get serious? Contemporary Ob/Gyn, 1 February 2014 https://www.contemporaryobgyn.net/modern-medicine-cases/placental-pathology-it-time-get-serious (accessed 08 June 2020)

7. Roberts DJ. Perinatal pathology: Practice suggestions for limited-resource settings. Arch Pathol Lab Med 2013;137(6):775-781. https://doi.org/10.5858\%2Farpa.2011-0560-sa

8. Redline RW, Heller D, Keating S, Kingom J. Placental diagnostic criteria and clinical correlation - a workshop report. Placenta 2005;26:S114-S117. https://doi.org/10.1016\%2Fj.placenta.2005.02.009

9. Malusi Z, Schubert PT, Theron GB, Wright CA. The value of histopathology of the placenta in tertiary referral hospital in South Africa. S Afr J Obstet Gynaecol 2019;25(2):64-67. https://do org/10.7196\%2Fsajog. 1434

10. Rabie U. The contribution of the placenta to the diagnosis of congenital tuberculosis. MMed thesis. Stellenbosch: University of Stellenbosch, 2014.1-98.https://hdl.handle.net/10019.1/86623

11. Kalk E, Schubert P, Bettinger JA, et al. Placental pathology in HIV infection at term: A comparison with HIV-uninfected women. Trop Med Int Health 2017;22(5):604-613. https://doi.org/10.1111\%2Ftmi.12858

12. Khong TY, Mooney EE, Ariel I, et al. Sampling and definitions of placental lesions Amsterdam placental workshop group consensus statement. Arch Pathol Lab Med 2016;140(7):698-713. https:// doi.org/10.5858\%2Farpa.2015-0225-cc

13. Pinar H, Sung CJ, Oyer CE, Singer DB. Reference values for singleton and twin placental weights Fetal Paed Pathol 1996;16(6):901-907. https://doi.org/10.3109\%2F15513819609168713

14. Erasmus N. Slaves of the state - medical internship and community service in South Africa. S Af Med J 2012;102(8):655-658. https://doi.org/10.7196\%2Fsamj.5987

15. Hargitai B, Marton T, Cox PM. Examination of the human placenta. J Clin Pathol 2004;57(8):785792. https://doi.org/10.1136\%2Fjcp.2003.014217

16. Government of South Australia. Histopathology management of the placenta. South Australian perinatal practice guideline 2016. Adelaide: Department for Health and Wellbeing, 2016. https:/ www.sahealth.sa.gov.au/wps/wcm/connect/a53e7080440106ec9ec6be1013b2c54b/Histopathology Management+of+the+Placenta_PPG_v2_0.pdf?MOD=AJPERES\&amp;CACHEID=ROOTWORK SPACE-a53e7080440106ec9ec6be1013b2c54b-n5iIw5

17. Ramokolo V, Malaba T, Rhoda N, Kauchali S, Goga A. A landscape analysis of preterm birth in South Africa: Systemic gaps and solutions. S Afr Health Rev 2019;2019(1):133-144. https:// www.hst.org.za/publications/South\%20African\%20Health\%20Reviews/12\%20SAHR_2019_A\%20 landscape\%20analysis $\% 20$ of\%20preterm\%20birth.pdf

18. Redline RW, Boyd TK, Roberts DJ, eds. Placental and Gestational Pathology. 1st ed. Cambridge University Press, 2017:62-69. https://doi.org/10.1017\%2F9781316848616

19. Roberts DJ, Post MD. The placenta in pre-eclampsia and intrauterine growth restriction. J Clin Pathol 2008;61(12):1254-1260. https://doi.org/10.1136\%2Fjcp.2008.055236

20. Bustamante Helfrich B, Chilukuri N, He H, et al. Maternal vascular malperfusion of the placenta bed associated with hypertensive disorders in the Boston Birth Cohort. Placenta 2017;52:106-113. https://doi.org/10.1016\%2Fj.placenta.2017.02.016

21. Egan BM, Kjeldsen SE, Grassi G, Esler M, Mancia G. The global burden of hypertension exceed 1.4 billion people: Should a systolic blood pressure target below 130 become the universal standard? J Hypertens 2019;37(6):1148-1153. https://doi.org/10.1097\%2Fhih.0000000000002021

22. Mayosi BM, Flisher AJ, Lalloo UG, Sitas F, Tollman SM, Bradshaw D. The burden of non communicable diseases in South Africa. Lancet 2009;374(9693):934-947. https://doi.org/10.1016\% 2Fs0140-6736\%2809\%2961087-4

23. Moodley J, Onyangunga OA, Maharaj NR. Hypertensive disorders in primigravid black Sout African women: A one-year descriptive analysis. Hypertension Pregnancy 2016;35(4):529-535. https://doi.org/10.1080\%2F10641955.2016.1193190
24. Madhi SA, Briner C, Maswime S, et al. Causes of stillbirths among women from South Africa: A prospective, observational study. Lancet Glob Heal 2019;7(4):e503-e512. https://dol. org $/ 10.1016 \% 2 \mathrm{Fs} 2214-109 \mathrm{x} \% 2818 \% 2930541-2$

25. National Department of Health (NDoH). National Committee on Confidental Enquirie into Maternal Deaths. Saving mothers 2017: Annual report on confidential inquiries into maternal death in South Africa. Pretoria: NDoH, 2017. http://www.health.gov.za/index.php/ shortcodes/2015-03-29-10-42-47/2015-04-30-08-18-10/2015-04-30-08-24-27/category/559-savingmothers?download=3414:2017-saving-mothers-annual-report (accessed 08 June 2020).

26. Burger R, Christian C. Access to health care in post-apartheid South Africa: Availability, affordability, acceptability. Heal Econ Policy Law 2020;15(1):43-55. https://doi. org $/ 10.1017 \% 2 \mathrm{Fs} 1744133118000300$

27. Ataguba JE, Akazili J, McIntyre D. Socioeconomic-related health inequality in South Africa: Evidence from general household surveys. Int J Equity Health 2011;10(1):48. https://doi org/10.1186\%2F $1475-9276-10-48$

28. Mchunu G, Peltzer K, Tutshana B, Seutlwadi L. Adolescent pregnancy and associated factors in South African youth. Afr Health Sci 2013;12(4):426-434. https://doi.org/10.4314\%2Fahs.v12i4.5

29. Lince-Deroche N, Pleaner M, Morroni C, et al. Achieving universal access to sexual and reproductive health services: The potential and pitfalls for contraceptive services in South Africa. S Afr Healt $\operatorname{Rev}$ 2016;2016(1):95-108. https://www.hst.org.za/publications/South\%20African\%20Health\%20 Reviews/9\%20Achieving\%20universal $\% 20$ access $\% 20$ to $\% 20$ sexual $\% 20$ and $\% 20$ reproductive $\% 20$ health\%20services.pdf

30. Redline RW, Boyd TK, Roberts DJ, eds. Placental and Gestational Pathology. 1st ed. Cambridge University Press, 2017:137-151. https://doi.org/10.1017\%2F9781316848616

31. Bioart Fertility Clinic. IVF treatment costs: What you need to know. 2019. https://bioartfertility. co.za/ivf-treatment-costs-what-you-need-to-know/ (accessed 08 June 2020).

32. 1Life. The high cost of infertility treatment. 2016. https://www.1life.co.za/blog/cost-fertilitytreatment (accessed 08 June 2020).

33. Altemani A, Gonzatti AMK. How many paraffin blocks are necessary to detect villitis? Placenta 2003;24(1):116-117. https://doi.org/10.1053\%2Fplac.2002.0875

34. Redline RW, Abramowsky C. Clinical and pathologic aspects of recurrent placental villitis. Hum Pathol 1985;16(7):727-731. https://doi.org/10.1016\%2Fs0046-8177\%2885\%2980159-3

35. Gebhardt GS, Fawcus S, Moodley J, Farina Z. Maternal death and caesarean section in South Africa: Results from the 2011 - 2013 Saving Mothers Report of the National Committee fo Confidential Enquiries into Maternal Deaths. S Afr Med J 2015;105(4):287-291. https://doi. org/10.7196\%2Fsamj. 935

36. Bateman C. Rendering unto Caesar? S Afr Med J 2004;94(10):800-802. http://www.samj.org.za/ index.php/samj/article/viewFile/2853/2055 (accessed 08 June 2020).

37. Africa Check. South Africa's C-section rate double what it should be? There's no recommended rate, says WHO. 2020. https://africacheck.org/reports/south-africas-c-section-rate-double-what-itshould-be-theres-no-recommended-rate-says-who/ (accessed 08 June 2020).

38. Redline RW, Ravishankar S. Fetal vascular malperfusion, an update. APMIS 2018;126(7):561-569 https://doi.org/10.1111\%2Fapm.12849

39. Khong TY, Ting M, Gordijn SJ. Placental pathology and clinical trials: Histopathology data from prior and study pregnancies may improve analysis. Placenta 2017;52:58-61. https://doi. org/10.1016\%2Fj.placenta.2017.02.014

40. Turowski G, Parks TW, Arbuckle S, Jacobsen AF, Heazell A. The structure and utility of the placental pathology report. APMIS 2018;126(7):638-646. https://doi.org/10.1111\%2Fapm.12842

41. Turner BJ, Laine C. Differences between generalists and specialists: Knowledge, realism, o primum non nocere? J Gen Intern Med 2001;16(6):422-424. https://doi.org/10.1046\%2Fj.15251497.2001.016006422

42. Kirkham N. The pathologist in the 21st century - generalist or specialist? J Clin Pathol 2000;53(1):7 9. https://doi.org/10.1136\%2Fjcp.53.1.7

43. Kaschula ROC. The practice of pathology in Africa. Arch Pathol Lab Med 2013;137(6):752-755. https://doi.org/10.5858\%2Farpa.2011-0587-ed

44. Schlingman JP. Critical shortage of pathologists in Africa triggers calls for more training programs and incentives to increase the number of skilled histopathologists. https://www.darkdaily. com/critical-shortage-of-pathologists-in-africa-triggers-calls-for-more-training-programs-andincentives-to-increase-the-number-of-skilled-histopathologists/ (accessed 08 June 2020).

45. Rispel L, Setswe G. Stewardship: Protecting the public's health. S Afr Health Rev 2007;(1):3-18 https://www.hst.org.za/publications/South\%20African\%20Health\%20Reviews/SAHR2007.pdf

46. Redline RW, Boyd TK, Roberts DJ, eds. Placental and gestational pathology. 1st ed. Cambridge University Press, 2017:115-136. https://doi.org/10.1017\%2F9781316848616

47. Fowler J, Simon L. Chorioamnionitis. In: StatPearls. Treasure Island: StatPearls Publishing, 2020 https://www.ncbi.nlm.nih.gov/books/NBK532251/

48. Dangor Z, Lala SG, Madhi SA. Preventing invasive Group B Streptococcus (GBS) disease in South African infants: Time for change. S Afr J Child Health 2015;9(3):69-70. https://doi. org $/ 10.7196 \% 2$ Fsajch. 8575

49. Quan V, Verani JR, Cohen C, et al. Invasive group B streptococcal disease in South Africa: Importance of surveillance methodology. PLoS ONE 2016;11(4):e0152524-e0152524. https://doi. org/10.1371\%2Fjournal.pone. 0152524

50. Dzanibe S, Madhi SA. Systematic review of the clinical development of group B Streptococcus serotype-specific capsular polysaccharide-based vaccines. Expert Rev Vaccines 2018;17(7):635-651. https://doi.org/10.1080\%2F14760584.2018.1496021

51. Bateman C. Discard the placenta at your peril, pathologist warns doctors. S Afr Med 2014;104(11):729-730. https://doi.org/10.7196\%2Fsamj.8991

Accepted 25 November 2020 